\title{
Lipid biomarkers: linking the utilization of frontal plankton biomass to enhanced condition of juvenile North Sea cod
}

\author{
M. A. St. John ${ }^{1, *}$, T. Lund ${ }^{2}$ \\ ${ }^{1}$ Danish Institute for Fisheries Research, Charlottenlund Slot, DK-2920 Charlottenlund, Denmark \\ ${ }^{2}$ University of Roskilde, Institute of Chemistry and Life Sciences, Postbox 260, DK-4000 Roskilde, Denmark
}

\begin{abstract}
The effects of physical mixing processes on phytoplankton production in the marne environment are well established. However, the effects of these processes on growth and condition of zooplankton and larval fish are at present poorly understood. In this study, we utilized phytoplankton group-specific fatty acid content to trace the phytoplankton group and mixing regime contributing to the condition of individual juvenile North Sea cod. In order to establish a relationship between lipid tracer content and algal utilization, post yolk-sac larval North Sea cod were reared in the laboratory on food chains based on monocultures of either the diatom Skeletonema costatum or the dinoflagellate Heterocapsa triquetra (algae dominatung in the mixed and stratified regions of the North Sea). In the laboratory, these algae were fed to cultures of adult Acartia tonsa, the copepod eggs were collected, hatched and the N1 nauplil from these different feeding regimes fed to post yolk-sac larval North Sea cod. Post yolk-sac larval cod required $8 \mathrm{~d}$ on either a Heterocapsa- or Skeletonema-based food chain before tracer lipid signals (the ratio of the lipids $16: 1 \omega 7$ to $16: 0$ ) in the larvae began to change from their original values to those similar to the algae at the base of their respectuve food chains. The cod larvae displayed a lipid tracer content similar to that of theur algal food source after $13 \mathrm{~d}$ on their respective feeding regimes. Durnng a cruise in May 1992 to examine the distribution of larval and juvenile North Sea cod, a subsample of 100 juvenile cod from the stratified, mixed and frontal regimes of the northeastern North Sea were examined for their content of lipid biomarkers and condition (as determined by the ratio of total lipid content to total length). Juvenile cod displaying a lipid tracer content indicating utilization of diatom-based food webs (found in proximity to regions of frontal mixing) were observed to be in significantly better condition $(\mathrm{p} \leq 0.05)$ than those containing a lipid signal indicative of utilization of flayellate-based food webs (found in stratified regions of the North Sea).
\end{abstract}

KEY WORDS: Lipid biomarkers - Larval and juvenile cod - North Sea - Frontal processes - Lipid condition

\section{INTRODUCTION}

The effects of intermediate scale physical oceanographic processes such as tidal fronts, riverine plumes, and topographically induced mixing on the distribution and production of planktonic organisms and larval fish has been the focus of a large proportion of recent biological oceanographic research (e.g. Mackas et al. 1985, Legendre \& Demers 1984, Govoni 1993, ICES/ GLOBEC 1993, 1994). These physical processes have

•E-mail:msj@dfu.min.dk been linked to increases in phytoplankton and zooplankton production (e.g. Richardson 1985, Kiørboe \& Johansen 1986), thus potentially influencing the abundance of prey items available for larval and juvenile fish. However, studies linking these physical processes to enhanced growth and condition of larval and juvenile fish have been limited (e.g. ICES/GLOBEC 1993, 1994). Despite the lack of evidence linking frontal phytoplankton and zooplankton production to increased condition of higher trophic levels, frontal regions can contain high abundances of larval and juvenile fish and have been implicated with contributing to enhanced growth rates of individuals in these 
regions (e.g. Kiørboe et al. 1988, Govoni 1993, Munk 1993). The focus of the research presented here is the linkage of larval and juvenile fish food resource utilization biochemically (through lipid biomarkers) to the water mass-specific food source contributing to their condition. Establishment of a relationship between larval and juvenile fish growth and condition and specific oceanographic regimes may aid in understanding their effects on fisheries recruitment variability.

Mixing regions and the surrounding stable water masses have been typified by specific phytoplankton classes (Cushing 1989, Kiørboe 1991, 1993) which may potentially, due to phytoplankton class specific lipid biomarkers (Sargent et al. 1988), be utilized to identify the transfer of phytoplankton production to higher trophic levels. For example, in stratified water columns, species of the classes Chrysophyceae. Haptophyceae and Dinophyceae dominate the phytoplankton community. The lipid composition of these algae can be characterized by the presence of $18: 4 \omega 3$ and 18:5 $\omega 3$ fatty acids (Joseph 1975, Pohl \& Zurheide 1979, Sargent et al. 1985) which are essentially absent from diatoms (Pohl \& Zurheide 1979). Diatoms, which are the dominant phytoplankton group in mixing regions, are typified by their content of the fatty acids $16: 4$ and 20:5 33 (Ackman et al. 1964, Chuecas \& Riley 1969, Pohl \& Zurheide 1979), as well as by having a higher ratio of $16: 1 \omega 7$ to $16: 0$ fatty acids than other phytoplankton classes (Ackman et al. 1968, Pohl \& Zurheide 1979, Fraser et al. 1989). The conservative transfer of these tracer dietary fatty acids into neutral lipids in higher trophic levels was first demonstrated by Lee et al. (1971), based on feeding experiments with Calanus helgolandicus. These experiments resulted in dietary fatty acids being advanced as biological markers for identification of trophic interactions (e.g. Sargent et al, 1988). Support for the utilization of these biological markers to investigate the transfer of phytoplankton production to higher trophic levels has been presented for both marine zooplankton and fish. For example, Graeve et al. (1994) demonstrated diet induced changes in fatty acid composition of the Arctic copepods C. finmarchicus, C. hyperboreus and C. glacialis. These copepods were observed to change their tracer lipid content from that of a diatom or a dinoflagellate food source dependent upon the lipid content of the food resources presented to them. A number of studies have demonstrated the potential for utilizing fatty acid tracers to identify trophic interactions in marine fish species. Fraser et al. (1989) observed a reduction in the content of the fatty acid 18:4 103 (indicative of the classes Chrysophyceae, Haptophyceae and Dinophyceae as food resources) and an increase in the ratio of $16: 1 \omega 7 / 16: 0$ fatty acids (indicative of utilization of diatom food sources) in herring lar- vae as well as in zooplankton during an enclosed ecosystem study. The switch in the fatty acid composition of the herring larvae occurred when the phytoplankton species composition at the base of the food web changed from flagellate to diatom domination (Fraser et al. 1989). Klungsøyr et al. (1989) also utilized the content of the fatty acid $18: 2 \omega 6$ in cod larvae to suggest that lipids of phytoplankton origin formed an important part of the diet of larval cod during the first feeding period. These experiments clearly demonstrated the incorporation and turnover of dietary fatty acids, thereby verifying the utility of specific fatty acids as trophic biomarkers in the marine environment.

In this study we established through lab experiments the transfer of the phytoplankton class-specific ratio of 16:1 $17 / 16: 0$ fatty acids from phytoplankton through a copepod intermediary to larval North Sea cod. Secondly, we examined the fatty acid composition of sizefractionated plankton samples during a cruise in the North Sea to establish the existence of these fatty acid food web tracers in the various hydrodynamic regions of the northeastern North Sea. This region of the North Sea is typified by a number of mixing processes which result in frontal systems (e.g. Pingree 1978, Nielsen et al. 1993) utilized by key fisheries stocks such as cod, herring and sprat (e.g. Kiørboe et al. 1988, Munk 1993, Munk et al. 1995). Finally, during this cruise, individual juvenile cod captured in the northeastern North Sea were examined for their tracer lipid content in order to establish the food web/hydrodynamic regime which contributed to their condition at time of capture. We expected juvenile cod utilizing the diatom rich food webs found in and around the frontal regions of the North Sea to contain a higher ratio of 16:1 $1 / 116: 0$ fatty acids than those utilizing the flagellate food webs (found in the stratified regions), as well as to be in better condition due to the increased food availability.

\section{MATERIALS AND METHODS}

Lipid analysis. Methyl esters of fatty acids from the total lipids contained in the tissues of lab and field samples were prepared by saponification and methylation with methanolic boron trifluoride (Whyte 1988). Individual fatty acid methyl esters were identified on a Hewlett-Packard (HP) 5890 Gas Chromatograph equipped with a split/splitless injector and an autosampler. Modification of the Whyte (1988) procedure was performed to include the injection of the internal standards Heptadecanoic acid methyl ester (C17:0) and cholestane (Sigma), prior to the methanolysis of the lipids from samples. These fatty acid methyl esters were found to be absent from the cod tissues, thus allowing their utilization for the estimation of the mass 
of individual lipid components. An HP1 $12 \mathrm{~m}, 0.25 \mathrm{~mm}$ internal diameter, nonpolar GC-column splitless injection was used at an injection temperature of $250^{\circ} \mathrm{C}$, with a helium flow of $1.0 \mathrm{ml} \mathrm{m} \mathrm{m}^{-1}$, a temperature program of $100^{\circ} \mathrm{C}$ in $2 \min$ to $300^{\circ} \mathrm{C}$, and a rate of $5^{\circ} \mathrm{C}$ min $^{-1}$ Selected samples were also analyzed utilizing a polar DBWax column (Supelco Inc, Bellefonte, PA, USA). Fatty acid methyl esters were identified by comparison with retention times of methyl esters obtained from Sigma and Larodan (Malmö, Sweden) The following retention times $\left(R_{1}\right.$ min $\left.^{-1}\right)$ and mass response factors $\left(R_{\mathrm{x}}=A_{\mathrm{x}} / \mathrm{m}_{\mathrm{x}}\right)$ relative to the internal standard C17:0 were obtained: $\left(R_{\mathrm{l}}, R_{\mathrm{x}}\right)$ : C14:0 (14.50, $0.96) ; C 16: 1 \omega 7(18.16,0.97) ; C 16: 0(18.83,1.02) ; C 18: 4$ $(21.66,1.0) ; \mathrm{C} 18: 3 \omega 3(21.95,0.95) ; \mathrm{C} 18: 2 \omega 6(22.00$, $0.95) ; C 18: 1 \omega 9 \quad(22.16,1.04) ; C 18: 1 \omega 7 \quad(22.29,1.0)$;

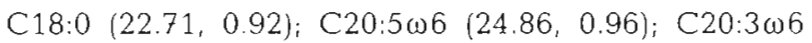
$(25.36,1.00) ; C 22: 6 \omega 3(27.90,0.61) ; C 22: 1 \omega 9$ (28.86, $0.94)$. In order to obtain sufficient material for quantification of lipid content, extractions were performed on a pooled sample composed of 5 larvae from the laboratory component of the study and on individual juveniles from the field study. The following fatty acid methyl esters were observed to be typical components of larval and juvenile North Sea cod: (1) C14:0; (2) $\mathrm{C} 16: 1 \omega 7$; (3) $\mathrm{C} 16: 0$; (4) $\mathrm{C} 18: 3 \omega 3$; (5) $\mathrm{C} 18: 4 \omega 3$;

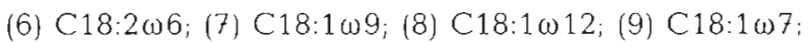

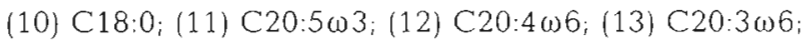

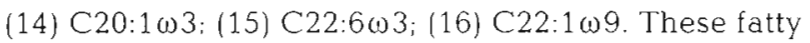
acid methyl esters were found to contribute more than $95 \%$ of the total fatty acid content of all larval and juvenile cod samples. Significant differences in the content of total lipids and tracer lipids during both the laboratory and field components of this study were established using Student $t$-tests (Sokal \& Rohlf 1981).

Laboratory study. Experiments were carried out in March 1992 on larval North Sea cod. Cod eggs came from a pooled sample of eggs and sperm from 5 females and 2 males with fertilization following the procedures outlined in Munk \& Rosenthal (1983). Temperature during incubation was maintained at $8.4( \pm 0.1)^{\circ} \mathrm{C}$ under constant illumination. After hatching and upon absorption of the yolk-sac by approximately $80 \%$ of the larvae, 600 larvae were transferred to each of 4 experimental tanks. Tanks were cylindrical (1 $\mathrm{m}$ diameter), composed of black polyethylene and contained 172 l of 27 ppt sea water The water tanks were double-walled with cooling water circulated inside the walls, allowing the water temperature inside the tanks to be maintained at $8.2( \pm 0.1)^{\circ} \mathrm{C}$ during the experiments. Filtered sea water ( $27 \mathrm{ppt}$ ) was continuously added to the tanks through 5 water jets throughout the water column. These jets mixed the water column, insuring a homogeneous distribution of nauplii prey items. Water was drained from the tanks utilizing a stand pipe with drainage occurring through a $20 \mu \mathrm{m}$ mesh nitex filter. Light from cool-white fluorescent tubes was gradually varied from 0 to $1000-1300 \mathrm{Lux}$ (at the water surface), as previously described by Stottrup \& Munk (1983) simulating a $24 \mathrm{~h}$ light-dark cycle ( $14.5 \mathrm{~h}$ light $\left.\mathrm{d}^{-1}\right)$. During the experiment, larvae were maintained under 4 experimental feeding regimes based on feeding the diatom Skeletonema costatum and the flagellate Heterocapsa triquetra (both commonly found in the mixed and stratified water masses of the North Sea) to cultures of adult Acartia tonsa. Semi-continuous cultures of these algae were raised under constant light and temperature (16.0 \pm $0.2^{\circ} \mathrm{C}$ ). Adult $A$. tonsa cultures were fed a diet of either $S$. costatum or $H$. triquetra from the aforementioned algal cultures, and their eggs were collected, enumerated and hatched following procedures outlined by Støttrup \& Munk (1983). Phytoplankton samples for determination of tracer lipid composition were obtained randomly throughout the study from both algal cultures. Algal samples for lipid content were filtered onto pre-combusted GF/C filters and stored at $-80^{\circ} \mathrm{C}$ under nitrogen gas prior to analysis. Lipid analysis was not performed on copepod eggs and nauplii during this study, as the transfer of tracer lipids from phytoplankton to copepods has been previously established for Calanus finmarchicus, C. hyperboreus and C. glacialis (Graeve et al. 1994) and for A. tonsa (St. John unpubl. data).

Post yolk-Sac, first feeding cod larvae were maintained under the following feeding regimes: (1) Heterocapsa-based food chain; (2) Skeletonema-based food chain; (3) mixed food chain of $50 \%$ nauplii from the Heterocapsa food source and $50 \%$ from the Skeletonema source; and (4) starved. Twenty cod larvae for lipid analysis were removed daily from all tanks at the beginning of the light cycle. Larvae were examined microscopically for evidence of feeding, measured for total length and then individually preserved in $1 \mathrm{ml}$ polyethylene Safelock tubes under nitrogen gas. Larval cod samples were then stored at $-80^{\circ} \mathrm{C}$ until analysis for lipid components. After the removal of the larval cod samples from the tanks, Acartia nauplii abundance was determined at 3 depths in each tank and the abundance of nauplii in each tank (excluding starvation trial) was raised to $200 \mathrm{~N} 1$ Acartia nauplii $\mathrm{l}^{-1}$

Field study. Juvenile cod ( $>1.2 \mathrm{~cm}$ standard length) were obtained during a multidisciplinary cruise, during which we examined the distribution of larval and juvenile cod and plankton production (primary and secondary), with respect to frontal mixing processes in the northeastern North Sea. The cruise was carried out from May 12 until June 1, 1992, with a total of 258 stations surveyed in the area $57^{\circ} 30^{\prime}$ to $56^{\circ} 00^{\prime} \mathrm{N}, 4^{\circ} 00^{\prime}$ to $9^{\circ} 30^{\prime} \mathrm{E}$. Stations were situated on a 
$10 \times 10$ nautical mile grid, as well as along transects selected to bisect areas of frontal mixing. Location of the study area and the transects examined are shown in Fig. 1A, B. At transect stations, in conjunction with samples for lipid analysis, samples were obtained to examine phytoplankton species composition and production, zooplankton species and production, larval and juvenile cod distribution, as well as physical oceanographic characteristics (e.g. salinity, temperature, water column stability and nutrient concentra-
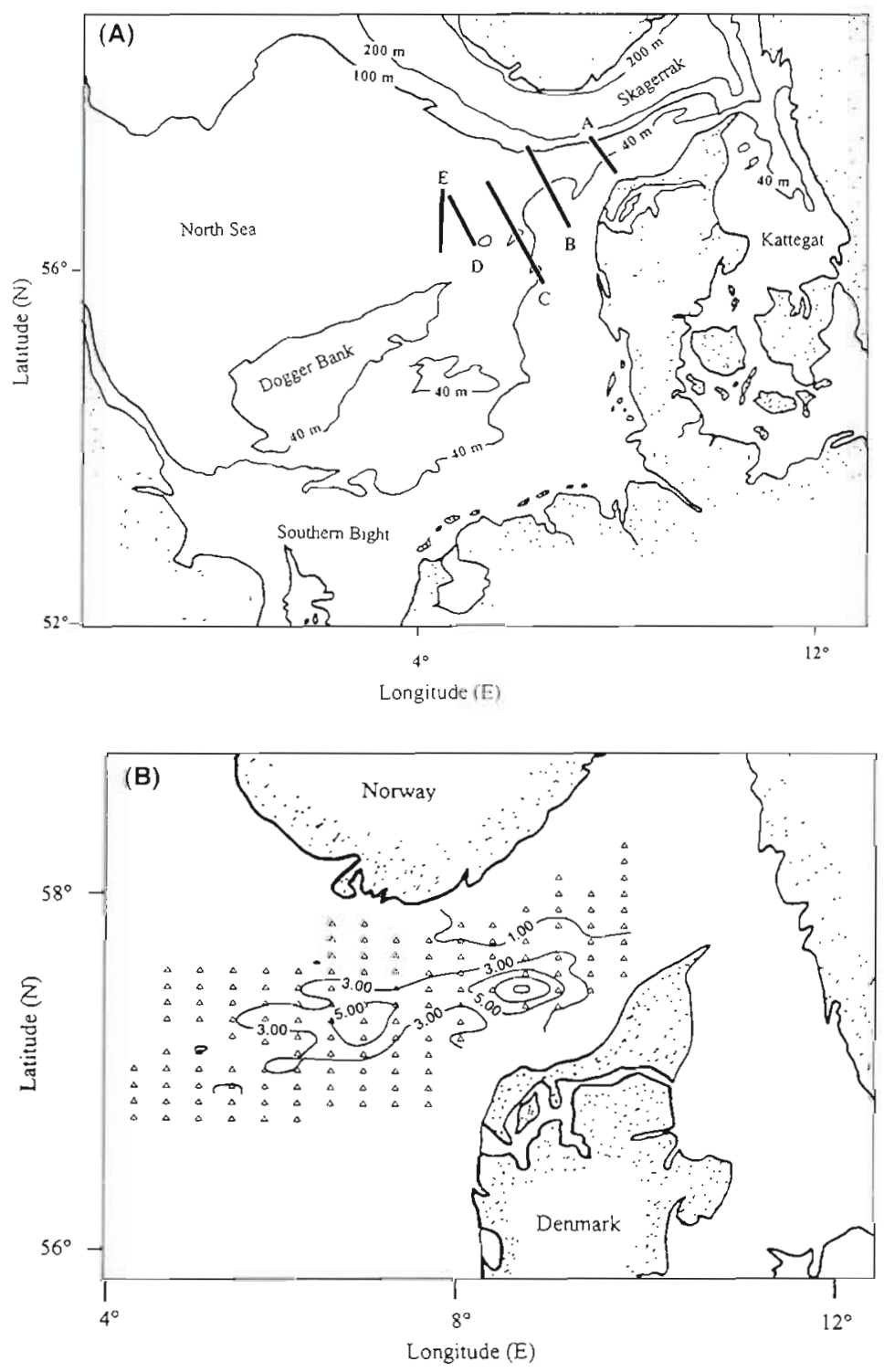

Fig. 1 (A) Location of the study site, bottom topography and transects examined during May 1992 in the North Sea. Heavy lines indicate transect positions. (B) Map of the study area and contours of concentration of chlorophyll a in the vorth Sea in May 1992. ( $\Delta$ ) Station positions and location of grid stations utilized in generating the contour plot of chlorophyll a (from Munk et al. 1995) Transect A shows the location of the transect utilized to generate the vertical contour plot of salinity and relative fluorescence shown in Fig. 3 tion). The techniques employed, the hydrographic properties and the distribution of larval and juvenile cod obtained in this study are presented in Munk et al. (1995) Juvenile cod abundances (>1.2 cm standard length) were determined by oblique hauls utilizing a $2.0 \mathrm{~m}$ diameter, $1.6 \mathrm{~mm}$ mesh size MIK $(1.5 \mathrm{~m}$ diam. ring) net. The net was deployed and retrieved at wire speeds of 25 and $15 \mathrm{~m} \mathrm{~min}^{-1}$, respectively, while ship speed was maintained at $1.5 \mathrm{~m} \mathrm{~s}^{-1}$. Estimates of the volume filtered per haul were determined, utilizing a flowmeter located in the center of the mouth opening. A subsample (650 fish) of the total catch of juvenile cod were obtained for analysis of lipid composition and morphometrics. Morphometric analysis (total length, head depth, eye diameter, body depth at midpoint and body depth at the anus) was performed immediately upon retrieval (5 fish per haul when available) prior to storage in liquid nitrogen for later determination of fatty acid content. In the laboratory, a random sample of 100 of these juvenile cod were weighed individually (wet weight) prior to extraction for determination of individual fatty acid. As otolith analysis was to be performed on these fish, the heads were removed and passively extracted in 2:1 chloroform:methanol for $24 \mathrm{~h}$ (held at $-20^{\circ} \mathrm{C}$ under nitrogen gas). The head extract was then added to the body, internal standards were added, and body and head extracts were homogenized in chloroform: methanol solution $(2: 1)$ for $2 \mathrm{~min}(2 \times 1 \mathrm{~min})$ on ice. Samples were then held at $-20^{\circ} \mathrm{C}$ under nitrogen gas for $24 \mathrm{~h}$ to complete lipid extraction prior to analysis for fatty acid composition. The condition of individual juvenile cod was estimated from the ratio of total lipids (structural components + storage components) to length (as an indicator of fish structural components) as previously described for larval striped bass (Martin et al. 1984). The utilization of structural to storage lipid condition indices has previously been demonstrated for juvenile cod by Suthers et al. (1992) and for larval anchovy (e.g. Håkanson 1989).

In order to examine how tracer fatty acid content of potential juvenile cod prey items varied between hydrodynamic regimes, size fractionated plankton samples (>350, 100-350, $60-100,43-60,20-43$, and $0.2-20 \mu \mathrm{m}$ ) for fatty acid determination were obtained at stations along transects crossing from the mixed to the stratified water column. Size fractions were chosen to roughly separate flagellates $(<20 \mu \mathrm{m})$ from diatoms and dinoflagellates $(>20$ to 
$<100 \mu \mathrm{m})$, as well as from micro- and macrozooplankton. Particles $>100 \mu \mathrm{m}$ were considered potential prey items for juvenile cod, with the dominant prey items considered to be those $>350 \mu \mathrm{m}$. The lipid composition of sizefractionated plankton samples (108 samples) was performed at 18 stations on 5 transects (Fig. 1B). At each station, a 201 Niskin bottle sample was obtained from the chlorophyll maximum for lipid analysis, with subsamples taken from this sample for determination of algal species composition. The volume sieved at each station was varied in order to allow sufficient biomass for lipid analysis. Samples of the larger plankton groups for lipid analysis were obtained in a vertical plankton haul $15 \mathrm{~m}$ off the bottom to the surface) with a SCOR net $(200 \mu \mathrm{m}$ mesh, haul speed $1 \mathrm{~m} \mathrm{~s}^{-1}$ ). The contents of the net haul was added to the water from the Niskin bottle samples and this volume sieved to separate into the individual size fractions. The sieved samples were then filtered onto combusted Whatman GF/C filters and stored in liquid nitrogen until transfer to a $-80^{\circ} \mathrm{C}$ Ultrafreeze in the laboratory prior to analysis for fatty acid components.

In order to examine the species composition of zooplankton, samples were collected by a submersible pump which filtered $1.2 \mathrm{~m}^{3} \mathrm{~min}^{-1}$ onto a $30 \mu \mathrm{m}$ mesh conical net. A vertical haul was performed with this apparatus from $5 \mathrm{~m}$ off the bottom to the surface at an ascent rate of $10 \mathrm{~m} \mathrm{~min}^{-1}$. Estimates of volume filtered were determined utilizing a flowmeter located in the center of the pump intake. Zooplankton samples were preserved in $4 \%$ buffered formalin with species composition and abundance determined microscopically in the laboratory.

\section{RESULTS}

\section{Laboratory study}

A total of 68 samples ( 5 cod larvae sample ${ }^{-1}$ ) were examined for the content of the fatty acids C16:1 17 and $\mathrm{C} 16: 0$ during the laboratory component of this study. The initial ratio of these lipids (16:167/16:0) in the cod larvae prior to exogenous feeding was 0.22 $(\mathrm{SD}=0.04, \mathrm{n}=4)$. A slight decline in the $16: 1 \omega 7 / 16: 0$ ratio of the cod larvae was observed from the beginning of the experiment (first feeding) until Day 7 in all treatments, but this decline is not significant $(p \geq 0.05$, $\mathrm{n}=8$ ) (Fig. 2). On Day 8, the ratio of $16: 1 \omega 7 / 16: 0$ tracer lipids in the cod larvae fed on the Skeletonemabased food chain began to increase. This trend continued until Day 13, after which these larvae displayed a ratio of $0.43(\mathrm{SD}=0.01, \mathrm{n}=4)$. The lipid tracer ratio after this time did not vary significantly $(\mathrm{p} \geq 0.05$, $\mathrm{n}=8$ ) from that of the cultures of Skeletonema (mean $0.43 ; \mathrm{SD} 0.02, \mathrm{n}=4$ ).

\section{Transfer of Lipid Food Web Tracers}

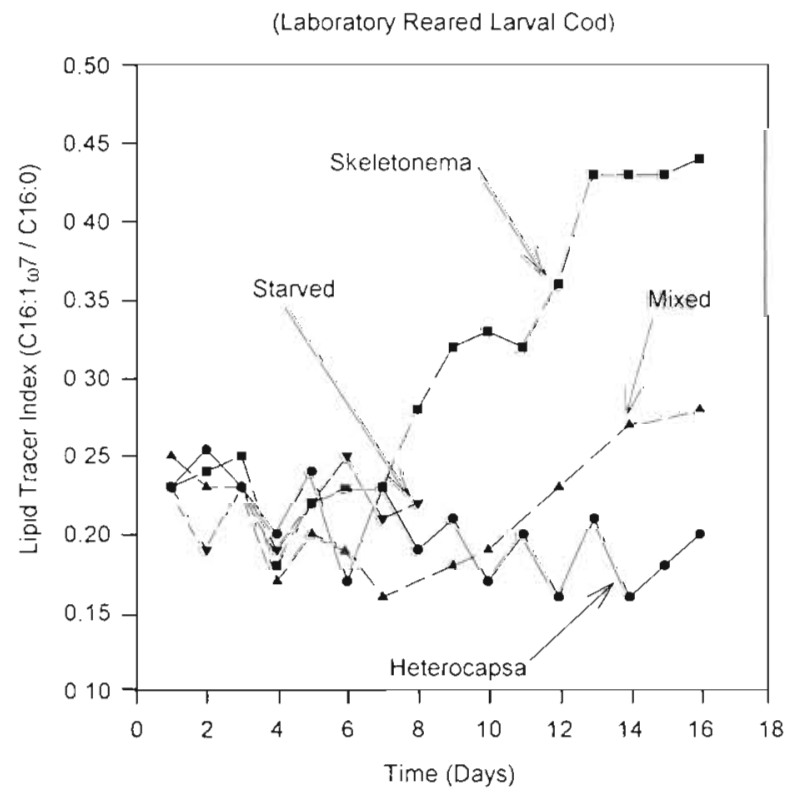

Fig. 2. Sixteen daytime series of the change in the ratio of the fatty acids 16:1 17 and 16:0 in larval North Sea cod raised on food chains consisting of Skeletonema costatum. Heterocapsa triquetra, a $50 \% \mathrm{mix}$ of both and no food, or starved. Algae were fed to adult Acartia tonsa, the copepod eggs collected and hatched and the nauplii were fed to the cod larvae. Each data point represents the ratio of $16: 1 \omega 7$ to $16: 0$ from a sample made up of 5 cod larvae

Cod larvae fed on the Heterocapsa-based food chain showed a downward trend in the ratio of $16: 1 \omega 7$ to 16:0 after Day 7. The mean ratio of these fatty acids after Day 13 was $0.19(S D=0.03, n=3)$, which was not significantly different $(p \geq 0.05, n=7)$ from the ratio of these fatty acids in the Heterocapsa cultures $(0.19$; $\mathrm{SD}=0.01, \mathrm{n}=4 \mathrm{l}$. Cod larvae fed on the mixed food regime containing $50 \%$ prey from Heterocapsa- and Skeletonema-based food chains, respectively, showed a steady increase in the ratio of $16: 1 \omega 7$ to $16: 0$ from Day 7 until Day 16, when the ratio observed was 0.29 which was intermediate between the different algal ratios (0.30). Starved larvae showed no significant change in the ratio of $16: 1 \omega 7$ to $16: 1$ over the $8 \mathrm{~d}$ that the larvae survived.

\section{Field study}

The study area, location of transects and the depthintegrated chlorophyll a ( $\mathrm{chl}$ a) concentration in the study region is presented in Fig. 1A, B. During this survey, a region of high chl a concentration was found to coincide with the $40 \mathrm{~m}$ depth contour (Fig. 1B), due to a tidal mixing front in this region (for a thorough description see Munk et al. 1995). A typical vertical 
contour plot of salinity along a transect bisecting the region of frontal mixing (Transect $A$, Fig. $1 B$ ) is presented in Fig. 3A, with Fig. 3B a plot of the djstribution of chl a along the same transect.

Phytoplankton species composition was similar along the transects shown in Fig. 1B stations with the diatoms Coscinodiscus sp. and Thalassiosira sp. and the dinoflagellate Ceratium sp. being the dominant species. The region of high chl a (Fig. $1 \mathrm{~B}$ and in the domed front (DF) region of Fig. $3 \mathrm{~B}$ ) was the result of high abundances of the diatoms Coscinodiscus sp. and Thalassiosira sp. (e.g. Fig. 3B). The inshore stable (IS) and offshore stable (OS) regions of high chl a (Fig. 3B) were the result of high abundances of diatoms (Coscinodiscus sp. and Thalassiosira sp.) and the dinoflagellate (Ceratium sp.). Calanoid copepods (Calanus finmarchicus, Temora longicornis, Pseudocalanus elongatus and Acartia sp.) dominated the mesozooplankton samples and were the dominant organisms $>350 \mu \mathrm{m}$ found in the pump samples.

\section{Size fractionated lipid samples}

The tracer lipid contents $(16: 1 \omega 7 / 16: 0)$ of size-fractionated plankton samples along Transect A (Fig. 1B) are presented in Table 1. Regions where phytoplank- ton biomass was dominated by diatoms (e.g. DF, Fig. 3B) contained a higher ratio of $16: 1 \omega 7 / 16: 0$ in the size fractions above $43 \mu \mathrm{m}(0.52 ; 43$ to $60 \mu \mathrm{m})$ than regions of mixed group domination (e.g. IS, Fig. 3B) $(0.34 ; 43$ to $60 \mu \mathrm{m})$ or regions of flagellate domination (OS, Fig. 3B) $(0.23 ; 43$ to $60 \mu \mathrm{m})$. This trend is especially evident in the 60 to $100 \mu \mathrm{m}$ size ranges in regions where diatoms were the most abundant (Table 1).

\section{Juvenile cod condition and lipid content}

A random sample of 100 juvenile $\operatorname{cod}(>1.2 \mathrm{~cm}$ total length) from the study region were analyzed for the content of the fatty acids $16: 1 \omega 7$ and 16:0 as well as for total fatty acid content. A least squares regression (Sokal \& Rohlf 1981) of the natural log of total fatty acid content (as determined from those fatty acids making up $95 \%$ of the fatty acid content) of individual fish versus natural log of total length was performed (Fig. 4), giving the equation $\operatorname{Ln} y=5.09+2.43 \operatorname{Ln} x(r=0.91)$ where $y$ is the total lipid content of the individual and $x$ is the total length at time of capture. Residuals of Ln total lipid content to Ln total length were calculated as deviations from this relationship and utilized as an indicator of the condition of individual fish. Examples of

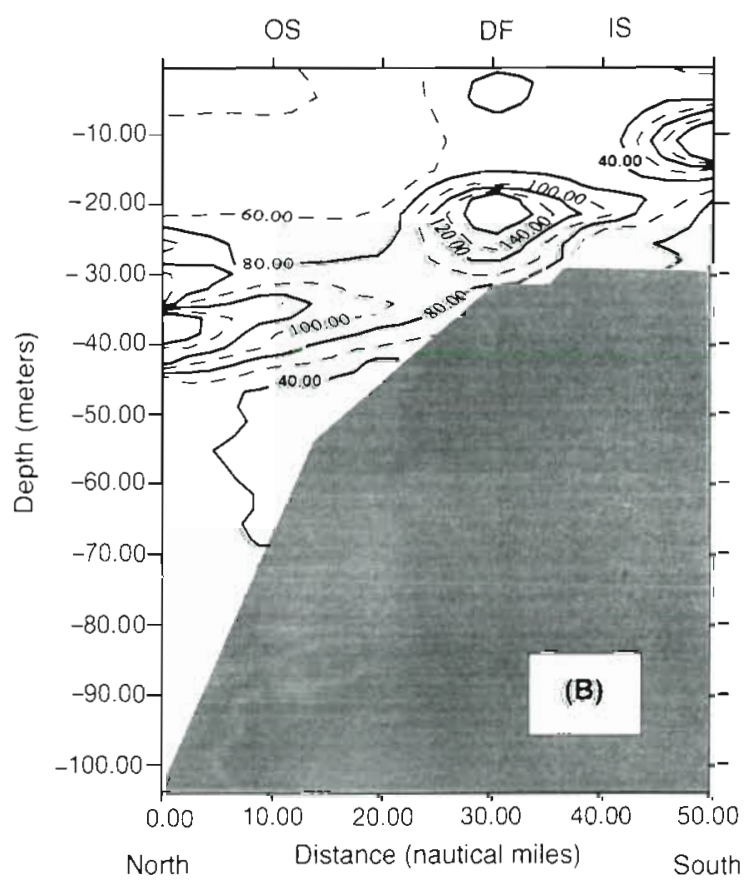

Fig. 3. Vertical contour plots of (A) salinity and (B) relative fluorescence along Transect A (Fig. 1A), showing positions of stations representing the inshore stratified region (IS), the domed front (DF) (note the doming of the 35.2 ppt isohaline), and the offshore stable (OS) regions of the North Sea. These stations were sampled to examine the tracer lipid content of size-fractionated plankton samples (see Table 1) 
Table 1. Ratio of $16: 1 \omega 7$ to $16: 0$ fatty acids in size-fractionated plankton samples on a transect across a mixing front in the North Sea, May 1992. Plankton samples were pooled from 201 Niskin bottle samples taken at the chlorophyll maximum and vertical plankton hauls from the pycnocline to the surface taken with a $200 \mu \mathrm{m}$ SCOR net. Station positions are indicated in Figs. $2 \& 8$

\begin{tabular}{|lccc|}
\hline $\begin{array}{l}\text { Size } \\
\text { fraction }\end{array}$ & $\begin{array}{c}\text { Mixed station } \\
\text { Mixed dominance }\end{array}$ & $\begin{array}{c}\text { Frontal station } \\
\text { Diatom dominance }\end{array}$ & $\begin{array}{c}\text { Stable station } \\
\text { Flagellate dominance }\end{array}$ \\
\hline$>350 \mu \mathrm{m}$ & 0.36 & 0.60 & 0.14 \\
$100-350 \mu \mathrm{m}$ & 0.47 & 1.15 & 0.23 \\
$60-100 \mu \mathrm{m}$ & 0.56 & 143 & 0.59 \\
$43-60 \mu \mathrm{m}$ & 0.34 & 0.52 & 0.23 \\
$20-43 \mu \mathrm{m}$ & 0.43 & 0.33 & 0.11 \\
$0.2-20 \mu \mathrm{m}$ & 0.27 & 0.23 & 0.16 \\
aDominant diatoms were Coscinodiscus sp. and Thalassiosira sp. \\
Dominant flagellate was Ceratium sp. \\
\hline
\end{tabular}

lipid to Ln total length) is shown in Fig. 6. The condition of individual cod showed the expected random distribution around the population mean, until the ratio of $16: 1 \omega 7$ to $16: 0$ exceeded 0.28 (Fig. 6). Once this value had been exceeded, all fish were above the mean condition of the population These data indicate that juvenile North Sea cod with an elevated ratio of $16: 1 \omega 7$ to $16: 0$ fatty acids (suggesting the utilization of diatom-based food webs) exhibit enhanced condition when compared to juvenile cod utilizing the flagellate-based food web in the more stratified regions of the North Sea. The plot of condition versus total

juvenile North Sea cod displaying a ratio of $16: 1 \omega 7$ to $16: 0$, with 0.36 and 0.13 representing a diatom and a flagellate signal, respectively, are presented in Fig. 5A, B. Peaks employed for determination of total fatty acid content are identified in this figure, as well as the fatty acids $16: 1 \omega 7$ and 16:0 which are utilized as the tracer lipid signal. The plot of the food web indicator $(16: 1 \omega 7 / 16: 0)$ versus the condition of individual juvenile cod (as determined from the residuals of Ln total

\section{North Sea Cod, May 1992}

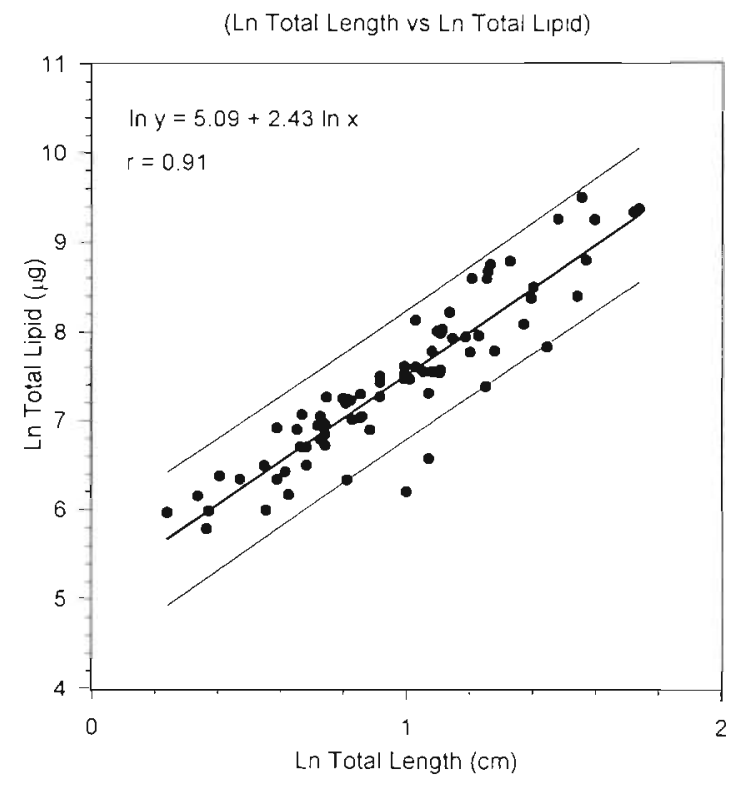

Fig. 4. Least squares regression of the natural log of total lipid content (as determined from fatty acids constituting $95 \%$ of the total fatty acid content) vs the natural log of total length of 100 juvenile North Sea cod captured in May 1992. Individual fish are a random subsample of 100 juvenile $\operatorname{cod}(>1.2 \mathrm{~cm}$ total length) of those caught at stations in Fig. $1 \mathrm{~B}$ as well as on transects across the regions of high chlorophyll a concentration seen in Fig. 1A, B length (Fig.7) shows no relationship; however, when these fish were examined for the ratio of $16: 1 \omega 7$ to $16: 0$, all fish except one inside the oval in Fig. 7 were found to have a ratio of $16: 1 \omega 7$ to $16: 0$ greater than 0.28 (note, all these fish were $>3.2 \mathrm{~cm}$ in total length). The mean condition, as expressed by the residuals of Ln total fatty acid versus $L n$ total length for fish with a $16: 1 \omega 7 / 16: 0$ of greater than 0.28 (>3.2 cm in total length) was 0.44 ( $\mathrm{n}=9$ ), which is significantly different ( $p \leq 0.05$ ) from those with a ratio less than 0.28 ( $>3.2 \mathrm{~cm}$ total length) which had a mean condition index of $0.21(n=11)$.

\section{DISCUSSION}

The results of the laboratory and field components of this study suggest that lipid biomarkers may prove to be important for identifying the relative contribution of different oceanographic food webs to larval fish growth and condition. Fraser et al. (1989) stated that to clarify the transfer of lipid biomarkers up the food web, the availability of tracer lipids in algae and the zooplankton prey of larval fish must be established before these tracers may be employed either quantitatively or qualitatively. We suggest from our results that these biomarkers may be suitable as a qualitative index of utilization of a specific food source in field studies; however, quantitative estimates of transfer between trophic levels in the field may prove to be difficult for a number of reasons. It is evident that a better understanding of the dynamics of lipid incorporation and utilization, with respect to environmental conditions such as temperature, light and nutrients in phytoplankton, as well as ontogeny in zooplankton and larval and juvenile fish, is required before these biomarkers may be used quantitatively. In phytoplankton, variations in tracer lipid signals have been observed within and between phytoplankton species in the same group 
(A)
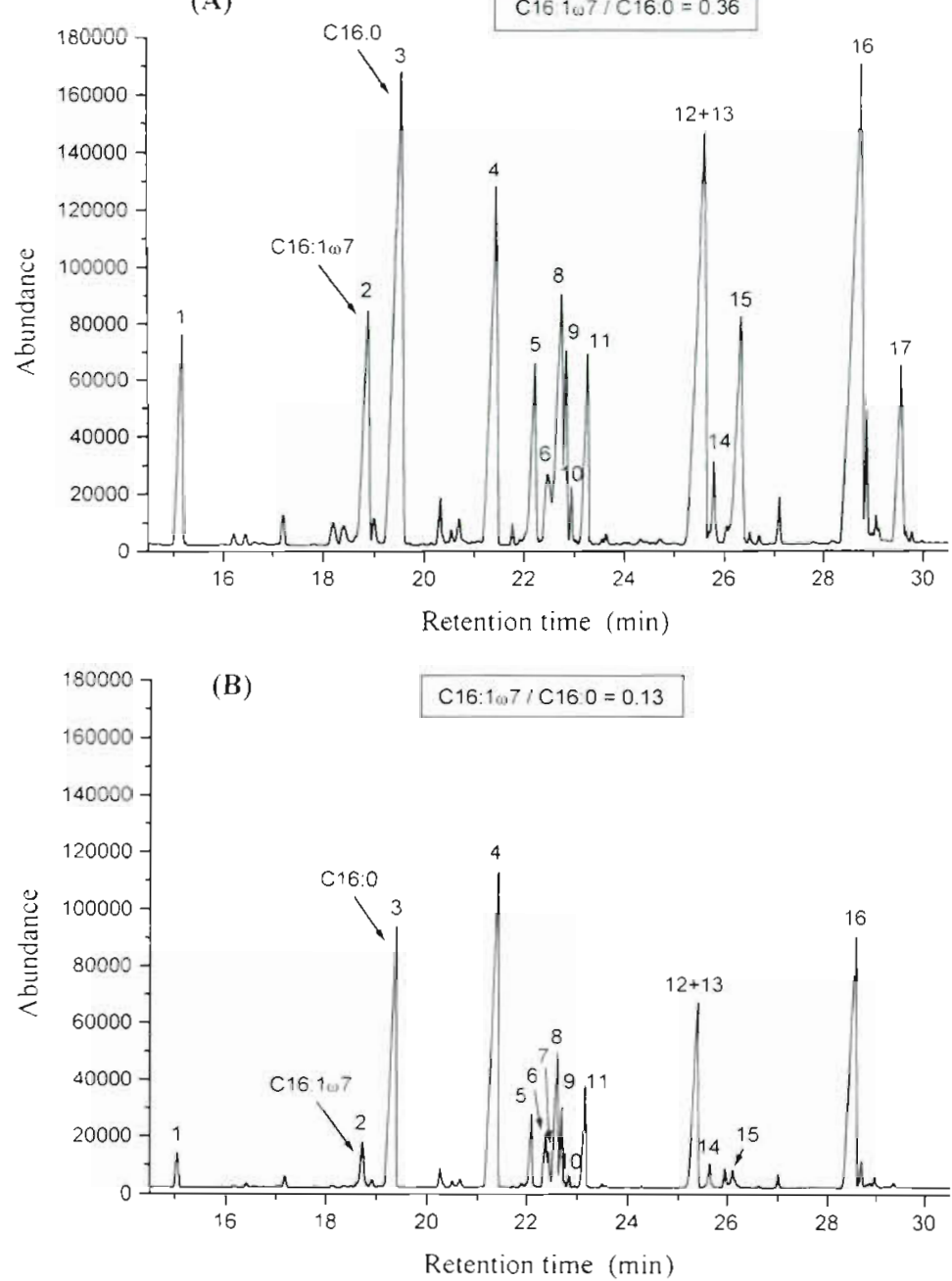

Fig. 5. Examples of lipid profiles of from juvenule North Sea cod in May 1992. Profiles were obtained on a coupled GC/FID utilizing an HP1 $12 \mathrm{~m}$ $0.25 \mathrm{~mm}$ internal diameter nonpolar GC-column and following fatty acid extraction procedures outlined in Whyte (1988). (A) Lipid profile of a juvenile cod demonstrating utilization of a diatom food web $(16: 1 \omega 7 / 16: 0=$ 0.36): (B) Lipid profile from a juvenile cod demonstrating utilization of a flagellate food web $(16: 1 \omega 7 / 16: 0=0.13)$. Individual lipids identified numerically are: (1) $C 14: 0 ;$ (2) $C 16: 1 \omega 7 ;$ (3) $C 16: 0 ;$ (4) 17.0 (Internal Stan-

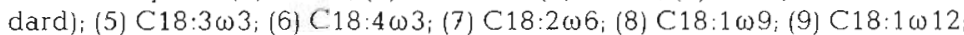

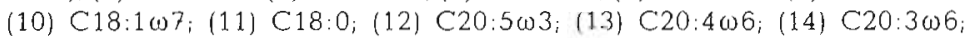
(15) $\mathrm{C} 20: 1 \omega 3 ;(16) \mathrm{C} 22: 6 \omega 3_{i}$ (17) $\mathrm{C} 22: 1 \omega 9$

(Ackman et al. 1964, Cheucas \& Riley 1969). In our study, the ratio of $16: 1 \omega 7$ to $16: 0$ of Skeletonema costatum was $0.43(\mathrm{SD}=0.02, \mathrm{n}=4$ ); other cultures of this species have had ratios $>2.0$ (Ackman et al. 1964, Cheucas \& Riley 1969). These observations can be attributed to variations in environmental conditions such as light. For example, Thompson \& Harrison (1992) observed ratios of $16: 1 \omega 7$ to $16: 0$ in Thalassiosira pseudonana cultures ranging from 1.06 to 2.30 depending upon the light regimes in which the algae were grown
Variations in the accumulation of lipids may also occur with changes in larval fish physiology. The results of the laboratory component of this study illustrate the transfer of the lipid tracers up the food chain (phytoplankton-copepod nauplii-larval cod) however, the time required to produce these changes is probably heavily dependent on larval physiology and developmental stage. In our study, the delay in evolution of the tracer signal until $7 \mathrm{~d}$ after first feeding was probably due to the lack of development of lipid deposits prior to this period. Kjørsvik et al. (1991) observed increased alimentary tract differentiation and gut epithelial folding in successful first feeding cod larvae with lipid absorption and possible temporary lipid storage in the anterior part of the gut at this time. Larvae observed during their study demonstrated a marked increase in occurrence and size of lipid vacuoles in bodies connected to the endoplasmic reticulum (mid gut) at Day 17 after hatch (approximately $12 \mathrm{~d}$ after first feeding), roughly corresponding to the period in our study where larvae exhibited the lipid ratio of their corresponding food source. Hence, the delay in incorporation of the lipid tracers may be due to inability of the larvae to store lipids prior to this stage.

In our laboratory study, we have qualitatively established the transfer of the tracer lipid ratio $(16: 1 \omega 7 / 16: 0)$ from a diatom source through a copepod intermediary and further up the food chain to larval cod. Comparison of the tracer lipid content of cod larvae from the mixed feeding regime $150 \%$ nauplii from each of the Skeletonema and Heterocapsa sources) suggests that a quantitative transfer took place However, caution should be employed as the dynamics of individual fatty acids during ontogeny is presently not clear for this species. Larval cod began to demonstrate a change in tracer lipid content $7 \mathrm{~d}$ after first feeding on their respective food sources. The tracer lipid content of the larvae evolved to match the lipid content of the algae, after $13 \mathrm{~d}$ in the case of the Skeletonema-based food web (Fig. 2). The transfer of the tracer lipids in the Heterocapsa triquetra trial occurred at similar times, although the results are less clear due to the variability of the larval cod lipid content during the study period (Fig. 2). However, the ratios of the fatty acids $16: 1 \omega 7$ and 16:0 observed in cod larvae maintained on the Skeletonema $(0.43 ; \mathrm{SD}=0.01, \mathrm{n}=4)$ and Heterocapsa $(0.19 ; \mathrm{SD}=$ 


\section{North Sea Cod, 1992}

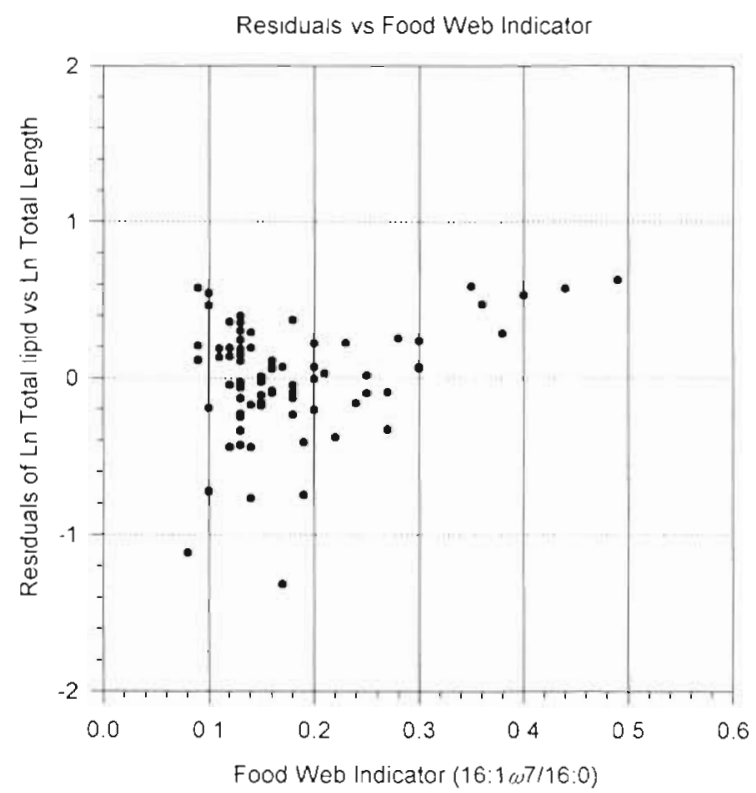

Fig. 6. Plot of condition (residuals of Ln total fatty acid content vs $\mathrm{L}$ total length, i.e. Fig. 4) against food web tracer (the content of the lipid tracer ratio 16:1 $1 / 7 / 16: 0)$ for a random sample of 100 juvenile North Sea cod (>1.0 cm total length) obtained in May 1992

$0.03, n=3$ ) food chains were significantly different $(p<$ $0.05)$ ) after Day 13. Cod larvae fed on a diet composed of nauplii fed on both of these algal sources also demonstrated changes in tracer lipid content on the same time scales as those fed on the monocultures. The $16: 107 / 16: 0$ ratio of these larvae $(0.29)$ was intermediate between that observed in the Skeletonema and Heterocapsa food chain larvae, suggesting the potential for these biomarkers to qualitatively identify the degree of utilization of different algal regimes.

The larvae which were starved maintained a relatively constant ratio of $16: 1 \omega 7 / 16: 0$, indicating that differential utilization of these 2 fatty acids was not occurring during starvation. This observation is similar to that of Martin et al. (1984) for larval striped bass, and suggests that larvae captured in the field, where feeding conditions are poor, will display the signal of the food web that contributed to existing lipid energy reserves.

Utilization of food web tracers for identifying the oceanographic process contributing to individual larval and juvenile fish condition in the field has also been presented here. The content of diatom tracer lipids found in juvenile cod exhibiting enhanced lipid stores (Fig. 5) suggests the potential importance of frontal plankton processes and diatom production for juvenile cod growth and condition. The low number of juveniles displaying the diatom lipid signal and their enhanced
North Sea Cod, 1992

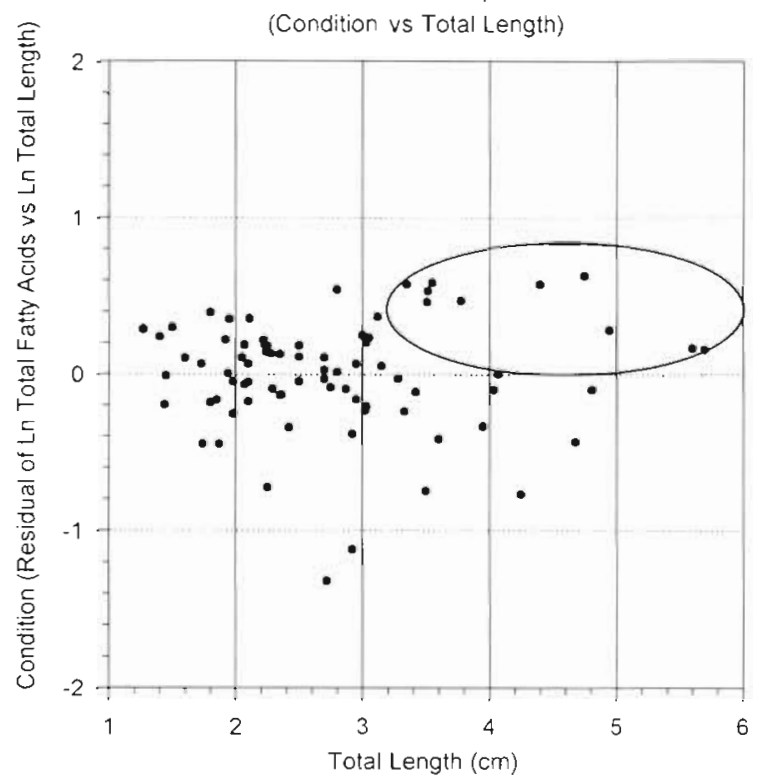

Fig. 7. Plot of condition (residuals of Ln total fatty acid content vs Ln total length, i.e. Fig. 4) against total length of the individual juvenile North Sea cod. All juvenule cod except one inside the oval have a tracer lipid content $>0.28$, indicating the utilization of diatom food resources The potential of dietary fatty acids as trophic biomarkers has been previously suggested (e.g. Sargent et al. 1988, Fraser et al. 1989), with support for their utilization as food web tracers demonstrated in laboratory experiments with copepods (e.g. Lee et al. 1971 Graeve et al. 1994). Comparisons of phytoplankton groupspecific fatty acid signatures and the fatty acid signatures of zooplankton presumed to be utilizing these food resources also support the utilization of these biomarkers to elucidate trophic interactions (e.g. Sargent et al. 1985, Fraser et al. 1989). Incorporation of dietary lipid food web tracers by larval fish has also been suggested by Fraser et al. (1989)

condition as compared to the rest of the population suggests that frontal plankton production may lead to enhanced condition due to increased food supplies.

The enhanced condition of the juvenile North Sea cod exhibiting utilization of diatom biomass suggests that these fish will potentially exhibit increased growth and reduced predation rates, as these larvae will be better able to avoid predators than fish of smaller size (e.g. Pepin et al. 1992). However, larger sized individuals may be subject to higher predation rates (e.g. Litvak \& Leggitt 1992, Pepin et al. 1992) leaving the net effects of higher growth rates on survival unclear.

The match in spatial and temporal occurrence of larval and juvenile fish with frontal plankton biomass during the critical early life history stages of fish requires further examination to determine if there is a relationship between frontal plankton dynamics and fisheries recruitment success. The utilization of lipid biomarkers as demonstrated in this study indicates a potential for 
linking larval and juvenile growth and condition not only to food type but also to the oceanographic regime contributing to the production of these food resources. The results of this study indicate that lipid biomarkers found in larval and juvenile fish and their prey may aid in linking variations in condition, growth and survival to processes which increase prey availability (ICES/GLOBEC 1994) or retain larvae in nursery regions (Sincläir \& Iles 1985). However, to confirm this relationship, more information is required on the turnover times of these lipid biomarkers in larval and juvenile cod and the food webs supporting them while these critical early life history stages of cod are undergoing changes in food consumption and ontogeny.

Acknowledgements. We thank Dr Katherine Richardson for making this research possible as well as Drs Thomas Kiørboe, Brian Mackenzie, Torkel Nielsen and Fleming Bo Peterson for scientific discussions and critical examination of the manuscript. We are extremely grateful to Peter Munk for making data and figures available to us from the cruise study as well as scientific discussions. We also thank the 2 anonymous reviewers who contributed greatly to the clarity of the article. Funding for M.A.St.J. was provided by the Danish National Science Foundation and the Danish Institute for Fisheries and Marine Research

\section{LITERATURE CITED}

Ackman RG, Jangaard PM, Hoyle RJ, Brokerhoff H (1964) Origin of marine fatty acids. I. Analysis of the fatty acids produced by the diatom Skeletonema costatum. J Res Fish Bd Can 21:747-756

Chuecas L, Riley JP (1969) Component fatty acids of the total lipids of some marine phytoplankton. J mar biol Ass UK 49:97-116

Cushing DH (1989) A difference in structure between ecosystems in strongly stratified waters and those that are only weakly stratified. J Plankton Res 11:1-13

Fraser AJ, Sargent JR, Gamble JC, Seaton DD (1989) Formation and transfer of fatty acids in an enclosed marine chain comprising phytoplankton, zooplankton and herring (Clupea harengus L.) larvae. Mar Chem 27:1-18

Govoni JJ (1993) Flux of larval fishes across frontal bound aries: examples from the Mississippi River plume front and the western Gulf Stream front in winter. Bull mar Sci 53: $538-566$

Graeve M, Kattner G, Hagen W (1994) Diet-induced changes in the fatty acid composition of Arctic herbivorous copepods: experimental evidence of trophic markers. J exp mar Biol Ecol 182:97-110

Håkanson JL (1989) Condition of larval anchovy (Engraulis mordax in the southern California Bight, as measured through lipid analysis. Mar Biol 102:53-59

ICES/GLOBEC (1993) Report of the ICES/GLOBEC Working Group on Cod and Climate Change, Lowestoft, UK, June 7-11, 1993. ICES CM 1993/G:3

ICES/GLOBEC (1994) Report of the ICES/GLOBEC Cod and Climate Change Aggregation Workshop, CharlottenIund, Denmark, August 22-24, 1994. ICES CM 1994/A:10

Joseph JD (1975) Identification of $3,6,9,12,15$-octadecapentaenoic acid in laboratory-cultured photosynthetic dinoflagellates. Lipids 10:395-403
Kiørboe T (1991) Pelagic fisheries and spatio-temporal variability in zooplankton productivity. Proceedings of the Fourth International Conference on Copepoda. Bull Plankton Soc Japan, Spec Vol, p 229-249

Kiørboe T (1993) Turbulence, phytoplankton cell size, and the structure of pelagic food webs. Adv mar Biol 29:1-72

Kiorboe T, Johansen K (1986) Studies of larval herring (Clupea harengus L.) patch in the Buchan area. IV. Zooplankton distribution and productivity in relation to hydrodynamic features. Dana 6:37-51

Kiørboe T, Munk P, Richardson K, Christensen V, Paulsen $H$ (1988) Plankton dynamics and herring larval growth, drift and survival in a frontal area. Mar Ecol Prog Ser 44: 205-219

Kjorsvik E, van der Meeren $T$, Kryvi $H_{1}$ Arnfinnsson J, Kvenseth PG (1991) Early development of the jaw and gut of cod larvae (Gadus morhua L.) during start-feeding. J Fish Biol 38:1-15

Klungsøyr J, Tilseth S, Wilhelmsen S, Falk-Petersen S, Sargent JR (1989) Fatty acid composition as an indicator of food intake in cod larvae Gadus morhua from Lofoten, northern Norway. Mar Biol 102:183-188

Lee RF, Nevenzel JC, Paffenhöfer GA (1971) Importance of wax esters and other lipids in the marine food chain: phytoplankton and copepods. Mar Biol 9:99-108

Legendre L, Demers S (1984) Towards dynamic biological oceanography and limnology. Can. J Fish Aquat Sci 41: $2-19$

Litvak MK, Leggett WC (1992) Age and size-selective predation on larval fishes: the bigger-is-better hypothesis revisited. Mar Ecol Prog Ser 31:13-24.

Mackas DL, Denman KL, Abbott MR (1985) Plankton patchiness: biology in the physical vernacular. Bull mar Sci 37 . 652-674

Martin FD, Wright DA, Means JC (1984) Fatty acids and starvation in larval striped bass (Morone saxatilis). Comp Biochem Physiol (77B) (4):785-790

Munk P (1993) Differential growth of larval sprat Sprattus sprattus across a tidal front in the Eastern North Sea. Mar Ecol Prog Ser 99:17-27

Munk P, Larsson PO, Danielsen D, Moksness E (1995) Larval and small juvenile cod Gadus morhua concentrated in the highly productive areas of a shelf break front. Mar Ecol Prog Ser 125:21-30

Munk P, Rosenthal H (1983) Variability in the size of herring larvae at hatching. Influence of egg density and parental material. Int Counc Explor Sea CM/L:33

Nielsen TG, Lokkegaard B, Richardson $K$, Pedersen FB, Hansen L (1993) Structure of plankton communities in the Dogger Bank area (North Sea) during a stratified situation. Mar Ecol Prog Ser 95:115-131

Pepin P, Shears TH, de Lafontaine Y (1992) Significance of body size to the interaction between a larval fish (Mallotus villosus) and a vertebrate predator (Gasterosteus aculeatus). Mar Ecol Prog Ser 81:1-12

Pingree RD (1978) Mixing and stabilization of phytoplankton distribution on the northwestern European Continental Shelf. In: Steele JH (ed) Spatial pattern in plankton communities. Plenum Press, New York, p 181-220

Pohl $P$, Zurheide $F(1979)$ Fatty acids and lipids of marine algae and the control of their biosynthesis by environmental factors. In: Hoppe HA, Levring T, Tanaka Y (eds) Marine algae in pharmaceutical science. Walter de Gruyer, Berlin, pp 473-523

Richardson K (1985) Plankton distribution and activity in the North Sea/Skagerrak-Kattegat frontal area in April 1984 Mar Ecol Prog Ser 26:233-244 
Sargent JR, Eilertsen HC, Faulk-Petersen S, Taasen JP (1985) Carbon assimilation and lipid production in phytoplankton in northern Norwegian fjords. Mar Biol 85:109-116 Sargent JR, Parks RJ, Mueller-Harvey I, Henderson RJ (1988) Lipid bionarkers in marine ecology. In: Sliegh MA (ed) Microbes in the sea. Ellis Horwood Ltd, Chichester, p 119-138

Sinclair M, Iles TO (1985) Atlantic herring (Clupea harengus) distributions in the Gulf of Maine-Scotian shelf area in relation to oceanographic features. Can J Fish Aquat Sci $42: 880-887$

Sokal RR, Rohlf FJ (1981) Biometry, 2nd edn. WH Freeman Co, New York

Støttrup JG, Munk P (1983) Cultivation technique for producing

This article was submitted to the editor copepods as food for fish larvae. Int Counc Explor Sea $\mathrm{CM} / \mathrm{F}: 20$

Suthers IM, Fraser A, Frank K (1992) Comparison of lipid, otolith and morphometric condition indices of pelagic juvenile cod Gadus morhua from the Canadian Atlantic. Mar Ecol Prog Ser 84:31-40

Thompson PA, Harrison PJ (1992) Effects of monospecific algal diets of varying biochemical composition on the growth and survival of Pacific oyster (Crassostrea gigas) larvae. Mar Biol 113:645-654

Whyte JNC (1988) Fatty acid profiles from direct methanolysis of lipids in tissues of cultured species. Aquaculture $75: 193-203$

Manuscript first received: May 30, 1994

Revised version accepted: August 1, 1995 